\title{
Reliability Assessment of Radial Distribution System
}

\author{
P.Sangeetha, S.Sowjanya
}

\begin{abstract}
In this paper the reliability indices are calculated for radial distribution network is improved by placing isolators. Isolators placed at near the tee section of the main radial distribution network used as protection for the load points under abnormal conditions. A seven load point distribution radial network is used to study without isolators and with isolators. Reliability indices evaluated and compared for radial network with isolators and without isolators.

Keywords: Reliability indices, radial distribution network, isolators, load points.
\end{abstract}

\section{INTRODUCTION}

Power system reliability mainly deals with the two terms adequacy and security [1].

- Adequacy related to the customer or consumer requirements such as load demand and quality of supply.

- Security related to the response of the system under abnormal conditions within the system.

Mainly according to the reliability three types of reliability exists in our power system network given below

- Generation system reliability

- Composite system reliability

- Distribution system reliability

Out of three types power distribution reliability is less when compared to power generation reliability and power transmission reliability.

Power is generated by generators is connected to the near grid then it is transmitted through transmission lines and is distributed through the substations are called power distribution substations.

Power distribution reliability is less because of the following reasons

- Occurrence of faults is more.

- Lack of distribution transformers maintenance.

- Lack of feeder monitoring, metering and

maintenance.

- Circuit breakers failures

In India according to central electricity authority limited every state discom(the state electric distribution company) has to report its day to day reliability parameters [4], feeder monitoring , feeder metering and feeder segregation.

Revised Manuscript Received on April 25, 2020.

* Correspondence Author

P.Sangeetha*, Assistant Professor, Department of Electrical \& Electronics Engineering,JNTUH College of Engineering, Jagtial, T.S.,India.

S.Sowjanya., Pursuing M.Tech, Electrical Power System, Jawaharlal Nehru Technological University Hyderabad College of Engineering Jagtial, T.S, India.

(c) The Authors. Published by Blue Eyes Intelligence Engineering and Sciences Publication (BEIESP). This is an open access article under the CC BY-NC-ND license (http://creativecommons.org/licenses/by-nc-nd/4.0/)
Outage it is defined as failure of power supply to the consumer for various reasons such as equipment failure, faults and any abnormal conditions of weather.

Outages mainly two types in our distribution network they are

- Scheduled outages

- Unscheduled outages

A. Scheduled Outages: These outages are planned outages for the system improvement, generally they are weekly or monthly planned outages, they include

- DT (distribution transformers) maintenance.

- Feeder checking, metering and measurement.

- Switches maintenance.

- Due to weather conditions

B. Unscheduled Outages: These are due to technical faults such as

- Short circuit faults

- Insulation failures

- Equipment failures

- Due to wrong connection of supply lines or switching of line.

In this paper a radial distribution network with seven load points [3] is considered for the reliability analysis. There are three basic reliability parameters such as average customer number of failures $(\lambda)$, average repair time (r) and annual average unavailability (U) used to calculate the reliability indices.

Reliability indices are mainly two types they are customer indices and load indices.

\section{RELIABILITY INDICES}

In reliability analysis different indices are calculated these indices indicate the performance of each load point, uninterruptible power, quality and safe. Monte carlo simulation methods [2] are also used to analyze the reliability.

Methods to improve reliability

- Communication system updating.

- Reinforcing a distribution network.

- Increasing the operating personnel.

- Placing new line in parallel with the existing network.

- Reconfiguration of the given network.

- Automation updating.

- Fast responding switches

- Switches placement

- Regular maintenance of all the protection and distribution equipment

- Reducing the losses

- Identification of faults. 


\section{Reliability Assessment of Radial Distribution System}

\section{A. System Average Interruption Duration Index (SAIDI)}

It is commonly used as a reliability indicator for electric power distribution systems.

SAIDI is the annual average outage duration for each customer served in that particular load center; SAIDI calculated as given below, units for SAIDI is also hours SAIDI $=\sum \mathbf{U}_{\mathbf{i}} * \mathbf{N i} / \mathbf{N}_{\mathbf{T}}$

Where $\mathbf{U}_{\mathbf{i}}$ is the duration of interruption of the ith load point and $\mathrm{Ni}$ is the number of customers in that load point. $\mathbf{N}_{\mathbf{T}}$ is the total number of customers served in all the load points of the power line. SAIDI (hours) is measured in time for which each customer is interrupted.

In order to increase the reliability of any state electricity distribution company failure rates $\left(\boldsymbol{\lambda}_{\mathbf{i}}\right)$ and repair times $\left(\mathrm{r}_{\mathrm{i}}\right)$ per month and per year should be as low as possible.

B. System Average Interruption frequency Index (SAIFI)

SAIFI it is also a reliability indicator which shows the number of times for which each customer is interrupted in a year

$$
\text { SAIFI }=\sum \lambda_{\mathbf{i}} * \mathbf{N}_{\mathbf{i}} / \mathbf{N}_{\mathrm{T}}
$$

Where $\boldsymbol{\lambda}_{\mathbf{i}}$ is the no. of failures in the ith load point and $\mathrm{N}_{\mathrm{i}}$ is the number of customers in that load point. $\mathrm{N}_{\mathrm{T}}$ and is the total number of customers served in all load points of the power line.

SAIFI (number of failures /year) is measured in units of no of interruptions per customer year.

\section{Customer Average Interruption Duration Index (CAIDI)}

CAIDI is similar to the SAIDI evaluated in hours, but it indicates average number of hours per customer year.

$$
\text { CAIDI }=\sum \mathbf{U}_{\mathbf{i}} * \mathbf{N}_{\mathbf{i}} / \sum \boldsymbol{\lambda}_{\mathbf{i}} * \mathbf{N}_{\mathbf{i}}
$$

\section{Unavailability $\left(\mathrm{U}_{\mathrm{i}}\right)$}

Annual unavailability is the product of failure rate and Repair time.

$\mathbf{U}_{\mathbf{i}}$ (Unavailability) $=\boldsymbol{\lambda}_{\mathbf{i}} * \mathbf{r}_{\mathbf{i}}$

Units of unavailability number of failure hours per customer year.

\section{E. Average Service Availability Index (ASAI)}

It is the average number of hour's availability per year

ASAI $=\left(\sum \mathrm{Ni}^{*} \mathbf{8 7 6 0}-\sum \mathrm{Ui}_{*} \mathrm{~L}_{\mathrm{i}}\right) / \sum \mathrm{Ni} * 8760$

F. Average Service Unavailability Index (ASUI)

It is the average number of hour's availability per year

$$
\text { ASUI=1-ASAI }
$$

\section{PROPOSED METHOD}

Generally distribution networks are radial in which feeders supply power to the customers, a radial distribution network with seven load points is shown in the fig. 1 is taken to analyze the reliability indices.

This radial network is having seven sections and seven load points. The network shown in the fig. 1 without isolators is studied as case-1.The radial distribution network with isolators is studied as case-2.

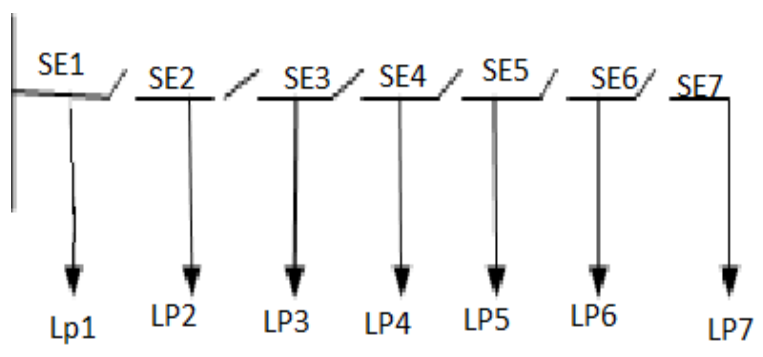

Fig.1.Shows the radial distribution network

Table-I:Indicats the parametrs of the line section

\begin{tabular}{|c|c|c|c|}
\hline Section & $\begin{array}{c}\text { Length } \\
(\mathrm{Km})\end{array}$ & $\begin{array}{c}\text { Failure Rate } \lambda \\
(\mathrm{f} / \mathrm{Yr})\end{array}$ & $\begin{array}{c}\text { Repair } \\
\text { Time } \mathrm{r}(\mathrm{hr})\end{array}$ \\
\hline $\mathrm{SE}_{1}$ & 1 & 0.065 & 5 \\
\hline $\mathrm{SE}_{2}$ & 1 & 0.065 & 5 \\
\hline $\mathrm{SE}_{3}$ & 1 & 0.065 & 5 \\
\hline $\mathrm{SE}_{4}$ & 3 & 0.195 & 5 \\
\hline $\mathrm{SE}_{5}$ & 2 & 0.13 & 5 \\
\hline $\mathrm{SE}_{6}$ & 1 & 0.065 & 5 \\
\hline $\mathrm{SE}_{7}$ & 1 & 0.065 & 5 \\
\hline
\end{tabular}

Table-II:Shows the data of the load points

\begin{tabular}{|c|c|c|}
\hline LP & Average Power (p.u) & $\begin{array}{c}\text { Number of } \\
\text { Customers }\end{array}$ \\
\hline LP1 & 0.0625 & 100 \\
\hline LP2 & 0.125 & 100 \\
\hline LP3 & 0.1875 & 200 \\
\hline LP4 & 0.3125 & 20 \\
\hline LP5 & 0.0625 & 100 \\
\hline LP6 & 0.125 & 10 \\
\hline LP7 & 0.125 & 20 \\
\hline
\end{tabular}

\section{Case 1}

The radial distribution network with seven load points is shown in the figure 1 . Using the line sectional parameters sown in the table 1 and load data from table 2 reliability indices are evaluated is studied as case 1. [4] [5]

Case 2

The radial distribution network is consists of series components such as line sections bus-bars and breakers. Perfect isolation of components and lines is done by the corresponding breakers is studied as case 2. [6]

\section{ANALYTICAL RESULTS}

Table-III:Shows the reliability parameters of the network

\begin{tabular}{|c|c|c|c|c|c|}
\hline Indices & SAIFI & SAIDI & CAIDI & ASAI & ASUI \\
\hline Case-1 & 0.65 & 3.25 & 5 & $\begin{array}{c}0.999 \\
6\end{array}$ & 0.0003 \\
\hline Case-2 & 0.249 & 1.246 & 5 & $\begin{array}{c}0.999 \\
8\end{array}$ & 0.0001 \\
\hline
\end{tabular}




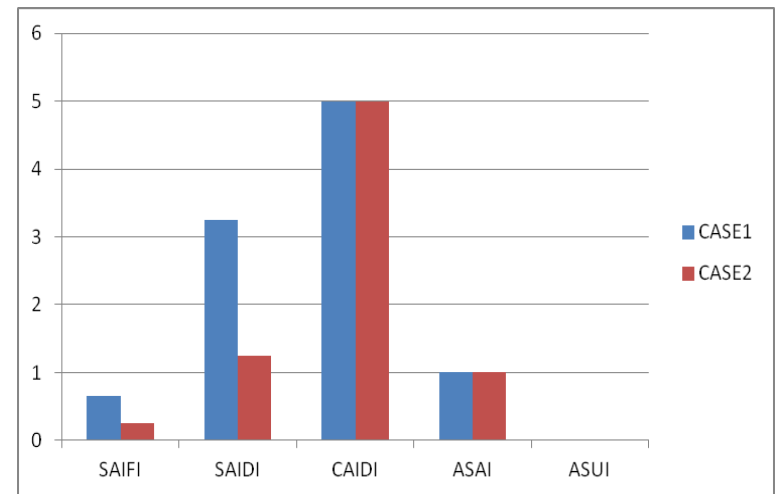

Fig.2.Comparison of reliability indices for case 1 and

Case 2

From the above results, it is observed that SAIDI decreased from case 1 to case 2 so that the load points for the considered radial distribution network are reliable in the second case.

\section{V.CONCLUSION}

For the radial distribution system load point indices and performance indices are calculated for two different cases and compared. In second case reliability of the system is improved and components of the radial network are protected by the perfect isolation.

\section{REFERENCES}

1. R. Billinton and R. N. Allan, Reliability evaluation of power systems, 2nd edition, Plenum Press, New York, 1996.

2. R. Billinton and E.Wojczynski, "Distributional variation of distribution system, reliability indices," IEEE Trans. Power Apparatus. Syst., vol. PAS-104, pp. 3152-3160, Nov. 1985.

3. S. X. Wang, Wei Zhao and Y. Y. Chen, "Distribution system reliability evaluation considering DG impacts," 2008 Third International Conference on Electric Utility Deregulation and Restructuring and Power Technologies, Nanjing, 2008, pp. 2603-2607.

4. R. Billinton and R. N. Allan, "Reliability Evaluation of Engineering Systems: Concepts and Techniques," Second Edition, Plenum Press, 1992.

5. Fotuhi-Firuzabad. M. Rajabi-Ghahnavie. A. An Analytical Method to Consider DG Impacts on Distribution System Reliability[C]. Transmission and Distribution Conference and Exhibition: Asia and Pacific, 2005 IEEE/PES, 2005, Page(s):1 6.

6. McDermott, T.E, Dugan, R.C. Distributed generation impact on reliability and power quality indices[C]. Rural Electric Power Conference, 2002 IEEE: D3 D3_7.

\section{AUTHORS PROFILE}

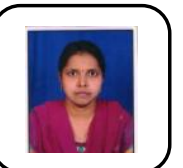

P. Sangeetha currently Working as an Assistant Professor, Department of Electrical \& Electronics Engineering,JNTUH College of Engineering, Jagtial, T.S.,India.E-mail:sangeetha813@gmail.com

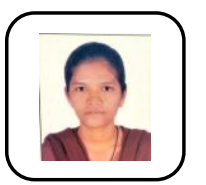

S. Sowjanya, she received the B.Tech degree in Electrical and Electronics Engineering in 2016, Pursuing M.Tech in Electrical Power System, Jawaharlal Nehru Technological University Hyderabad College of Engineering Jagtial, T.S, India. 